\title{
Correction to: Carbon Nanomaterials for Air and Water Remediation
}

\author{
Sergio Morales-Torres, Luisa M. Pastrana-Martínez, \\ and Francisco José Maldonado-Hódar
}

\section{Correction to:}

Chapter 12 in: M. Piumetti, S. Bensaid (eds.), Nanostructured Catalysts for Environmental Applications, https://doi.org/10.1007/978-3-030-58934-9_12

This book was inadvertently published with an incorrect reference [135] in Chapter 12. This has now been updated as follows.

BRILLAS, Enrique; MUR, Eva; CASADO, Juan. Iron (II) Catalysis of the Mineralization of Aniline Using a Carbon-PTFE O 2-Fed Cathode. Journal of the Electrochemical Society, 1996, vol. 143, no 3, p. L49.

The updated online version of this chapter can be found at https://doi.org/10.1007/978-3-030-58934-9_12 